\title{
Interruptions of Antiretroviral Therapy in HIV Infection: Are they Detrimental to Neurocognitive Functioning?
}

Jose A. Muñoz-Moreno, ${ }^{1,2}$ Carmina R. Fumaz, ${ }^{1,2}$ Anna Prats, ${ }^{1,2}$ Maria J. Ferrer, ${ }^{1,2}$ Eugènia Negredo, ${ }^{1,2}$ Núria Pérez-Álvarez, ${ }^{1,3}$ José Moltó, ${ }^{1,2}$ Guadalupe Gómez, ${ }^{3}$ Maite Garolera, ${ }^{4}$ and Bonaventura Clotet $^{1,2,5}$

${ }^{1}$ Lluita contra la SIDA Foundation - Germans Trias i Pujol University Hospital. Badalona, Barcelona, Catalonia, Spain

${ }^{2}$ Autònoma de Barcelona University. Barcelona, Catalonia, Spain

${ }^{3}$ Politècnica de Catalunya University. Barcelona, Catalonia, Spain

${ }^{4}$ Consorci Sanitari de Terrassa Hospital. Terrassa, Barcelona, Catalonia, Spain

${ }^{5}$ IrsiCaixa Foundation. Badalona, Barcelona, Catalonia, Spain

Address of corresponding author:

Jose A. Muñoz-Moreno, MS

Lluita contra la SIDA Foundation - HIV Unit

Germans Trias i Pujol University Hospital

Ctra. de Canyet, $S / N$

08916, Badalona, Barcelona, Catalonia, Spain

Tel: +3493465 7897

Fax: +34934657602

e-mail: jmunoz@flsida.org

Short title: Neurocognitive Functioning and Antiretroviral Treatment Interruptions

Keywords: Neurocognitive Functioning; Neuropsychological Assessment; Treatment Interruption; Antiretroviral Therapy; HIV Infection 


\begin{abstract}
Background: Since interruptions of antiretroviral treatment may entail clinical risks for HIV-infected individuals, we investigated their impact on neurocognitive functioning.

Methods: Cross-sectional study comparing HIV-infected persons who had interrupted antiretroviral therapy in the past (interruption group, IG) with persons who had never discontinued therapy (non-interruption group, NIG). Interruption was defined as the discontinuation of HAART for more than 15 days after previous treatment of at least 15 days. All the participants were on therapy. Demographic, clinical, and neurocognitive variables were assessed. The primary end point was the percentage of people with neurocognitive impairment. The score in different neurocognitive domains was a secondary end point.
\end{abstract}

Results: A total of 83 subjects participated in the study (IG: $n=27$, NIG: $n=56$ ). Demographic and clinical characteristics were balanced between the groups, except for years since HIV diagnosis (IG, 13.8; NIG, 10.2 [p=0.003]). The percentage of people with neurocognitive impairment was significantly higher in the IG group (IG, 59.25\%; NIG, $33.92 \%$ [p=0.02]). As for scores in neurocognitive domains, individuals in the IG showed worse neurocognitive functioning, and significant differences in attention/working memory and information processing speed were found. The adjusted analysis supported the unadjusted analysis.

Conclusions: In our study, a higher prevalence of neurocognitive impairment was detected in HIV-infected persons who had interrupted antiretroviral therapy in the past. Additionally, neurocognitive functioning was observed to be more impaired in the same individuals. Further studies should examine the potential negative effects of antiretroviral therapy interruptions on neurocognitive functioning. 


\section{Introduction}

Patients infected with human immunodeficiency virus (HIV) continue to experience impairment of neurocognitive functioning. While the incidence of most neurological complications has decreased since the introduction of highly active antiretroviral therapy (HAART), the prevalence of HIV-associated dementia (HAD) has not declined, and the incidence of milder neurocognitive disorders, such as mild neurocognitive disorder (MND) and asymptomatic neurocognitive impairment (ANI), has increased (Cysique et al, 2004; Sacktor et al, 2002; Tozzi et al, 2005a). Both observations are related to the persistence of HIV in the central nervous system (CNS) (Muñoz-Moreno et al, 2009; Spudich et al, 2005) and the inability of current antiretroviral therapy to effectively protect the CNS (Cysique et al, 2006; Tozzi et al, 2007), as well as the emergence of new potential risk factors, such as aging (Becker et al, 2004), nadir CD4 cell count (Muñoz-Moreno et al, 2008), and coinfection with hepatitis C virus (HCV) (Hilsabeck et al, 2005).

Treatment interruption in chronically HIV-infected individuals is often based on the patient's decision, although it has also been applied as a therapeutic strategy by clinicians to reduce antiretroviral-associated toxicity, improve quality of life, and reduce the economic burden of antiretroviral therapy for public health systems. However, despite these potential advantages, there is evidence of significant risks for individuals discontinuing treatment and of an association with increased morbidity and mortality (Danel et al, 2006; El-Sadr et al, 2006).

As little is known about the effect of treatment interruptions on neurocognitive functioning, we conducted a study to compare neurocognitive functioning in HIV-infected patients who had interrupted antiretroviral therapy with that of patients who had not. We assessed the prevalence of neurocognitive impairment and measures of neurocognitive functioning.

\section{Material and methods}

\section{Study design}

We designed an observational cross-sectional study to explore the effect of previous antiretroviral interruptions on neurocognitive functioning in chronically HIV-infected patients. Interruption was defined as discontinuation of antiretroviral treatment for more 
than 15 days after at least 15 days of treatment at any time during the course of the infection. This criterion was based on previous findings which indicate that viral replication could be feasible after a mean of 15 days (Ruíz et al, 2007). Therefore, all recruited participants were classified into 2 study groups: patients who had discontinued antiretroviral therapy in the past (interruption group, IG), and patients who had never interrupted therapy (non-interruption group, NIG).

The study was conducted in accordance with the Helsinki Declaration of 1964 (1996 revision) and Good Clinical Practice guidelines, and was approved by the research ethics committee of Germans Trias i Pujol University Hospital. Lluita Contra la SIDA Foundation was the principal study sponsor.

\section{Objectives}

The general objective of this study was to compare neurocognitive functioning in patients who had interrupted antiretroviral therapy in the past with those who had never interrupted therapy. We established two study end points:

- The primary end point was the prevalence of neurocognitive impairment. This was based on a comparison of the percentage of patients showing neurocognitive impairment in both groups.

- The secondary end point was based on neurocognitive scores covering relevant neurocognitive domains in HIV infection. Fourteen scores resulting from a comprehensive assessment of neurocognitive functioning were compared between study groups.

\section{Study participants}

The study population was composed of patients attended at the HIV Unit of the Germans Trias i Pujol University Hospital. Between March 2006 and September 2008, we informed all the patients about the objectives of the study and applied specific study criteria to select the definitive sample. All participants had to be at least 18 years old and receiving a HAART combination on inclusion. Those patients with a prior or current opportunistic infection involving the CNS were excluded, as were those who reported drug use or a prior or current psychiatric disorder. This was assessed at the initial information visit by the investigator responsible for recruitment, although the database of the HIV Unit was also checked to confirm the information reported by each patient. After recruitment, all 
participants made an appointment for a new visit, at which they were evaluated and data were collected.

\section{Measures and instruments}

Demographic, clinical, emotional, and neurocognitive variables were assessed. The demographic variables were recorded at the information visit and confirmed using our HIV Unit database. These data comprised age, gender, infection route, and years of education.

Clinical variables were extracted from the HIV Unit database and medical reports. In both study groups, these consisted of time since HIV diagnosis, time on treatment, current CD4 cell count, nadir CD4 cell count, viral load, and coinfection with HCV. In the IG, we recorded the following additional variables: number of interruptions, number of structured interruptions, duration of interruption, time since last interruption, and number of plasma viral rebounds. The number of structured treatment interruptions and viral rebounds were not included in the data analysis, although both variables were recorded to provide descriptive data on interruptions. A structured treatment interruption was considered to have finished when therapy was restarted at a CD4 cell count of $<350$ cells/mL or plasma viral load of $>100,000$ copies $/ \mathrm{mL}$, and when the patient had undergone at least 2 interruptions. Viral rebounds were defined as an increase in plasma viral load to $>35,000$ copies/mL during the month after interruption.

The emotional variables assessed were depression and anxiety. Depression was evaluated using the Beck Depression Inventory (BDI) (Beck et al, 1979)—specifically the cognitive-affective subscale for avoiding biases related to somatic symptoms (Beck et al, 1996) - and anxiety was evaluated by the State-Trait Anxiety Inventory (STAI) (Spielberger et al, 1970).

Neurocognitive variables were assessed using a neuropsychological test battery, as recommended for the assessment of neurocognitive functioning in HIV infection (MuñozMoreno, 2007). The tests included and neurocognitive domains assessed were as follows: the Letter-Numbers and Digits Tests of the Wechsler Adult Intelligence Scale-III (WAISIII) (Weschler, 1997) for attention/working memory; Part A of the Trail Making Test (TMT) (Reitan and Davidson, 1974) and the Symbol Digit Modalities Test (SDMT) (Smith, 1973) for information processing speed; the California Verbal Learning Test (CVLT) (Delis et al, 2000) for verbal memory and learning; Part B of the TMT (Reitan and 
Davidson, 1974), the Stroop Test (Golden, 1978), the Wisconsin Card Sorting Test (WCST) (Kongs et al, 1993), and the Tower of London (TOL) (Culbertson and Zillmer, 2001) for executive functions; the Controlled Oral Word Association Test (COWAT) (Benton et al, 1994) and the Animals Test (Gladsjo et al, 1999) for verbal fluency; and the Grooved Pegboard Test (Matthews and Klove, 1964) for motor function. Premorbid intelligence was also assessed using the Vocabulary Test of the WAIS-III (Weschler, 1997), although this variable was treated as a clinical variable, mainly to be included in equivalence analyses between groups. Self-reported neurocognitive complaints were also recorded. This was considered a dichotomized categorical variable (yes/no), when the patient reported symptoms of neurocognitive impairment.

Neurocognitive impairment was defined as performance of one standard deviation below the normative mean in at least two neuropsychological tests, or two standard deviations below the normative mean in at least one test, as extensively used in other studies assessing HIV-related neurocognitive impairment (Antinori et al, 2007; Cysique et al, 2004; Muñoz-Moreno et al, 2007; Muñoz-Moreno, 2008; Tozzi et al, 2005a). Impairment was considered mild when one standard deviation below the normative mean was observed in at least two tests or two standard deviations in one test, and moderatesevere when this was more than two standard deviations in one test or two deviations in more than two tests. $t$ scores were used for all comparisons and were obtained using a correction standardization process based on adjusting the raw scores according to age, gender and education, using normative data (Benton et al, 1994; Culbertson and Zillmer, 2001; Delis et al, 2000; Gladsjo et al, 1999; Golden, 2001; Kongs et al, 1993; Reitan and Wolfson, 1985a; Reitan and Wolfson, 1985b; Smith, 2002; Weschler, 1999).

The Frascati criteria proposed by Antinori et al (Antinori et al, 2007) were used to classify subjects in both groups according to the presence of HIV-associated neurocognitive disorders (HAND). This classification contemplated the existence of ANI, MND, and HAD. More specifically, in our work ANI and MND were identified when mild neurocognitive impairment involved at least two neurocognitive domains, and HAD when moderate-severe impairment was confirmed by the presence of self-reported neurocognitive complaints. The differentiation between ANI and MND was established according to the presence of neurocognitive complaints: MND involved the presence of neurocognitive complaints and ANI did not. 


\section{Data analysis}

Equivalence between groups was determined by the comparison of demographic, clinical, and emotional variables. Differences between groups were assessed using analysis of variance when quantitative variables showed a normal distribution (KolmogorovSmirnov test, $p$ values $>0.05$ ) and non-parametric tests (Mann-Whitney) when they were not normally distributed. A $\chi^{2}$ test was used to compare proportions. Regarding the neuropsychological measures in the seven domains, differences between groups were assessed using the means of each score.

Since this was an observational and cross-sectional investigation, the possibility of a lack of equivalence between groups was considered, and neuropsychological measures were adjusted using linear regression when demographic or clinical variables were not balanced. Additionally, Cohen's effect size tests $(d)$ (Cohen, 1988) were also performed to quantify the magnitude of the differences found. Values were considered small when scores were less than 0.40 , medium when they ranged between 0.40 and 0.75 , and large when they were over 0.75 .

All statistical analyses were performed using SPSS Statistics, v.17.0. (SPSS Inc, Chicago, Illinois, USA) and R, v.2.2.0. [http://www.r-project.org]) with a univariate twotailed significance level of $5 \%$.

\section{Results}

A total of 136 patients were informed and invited to participate in the study. Of these, 124 accepted and 83 fulfilled the study criteria (see Figure 1). Of the 83 eligible participants, 27 patients were assigned to the IG and 56 to NIG.

The demographic, emotional, and clinical characteristics of the participants are shown in Table 1. The study groups were statistically comparable, except for time since HIV diagnosis, which was greater for IG participants (IG, 13.8; NIG, 10.2 [ $p=0.003]$ ). Although some of the remaining demographic, emotional, and clinical variables showed differences in the distribution between groups, none of them reached statistical significance. The greatest differences were seen in time on treatment (IG: 8.2; NIG: 7 [ $p=0.09]$ ) and the scores for anxiety (IG, 47; NIG, $40[p=0.06]$ ). Other virological and immunological parameters such as plasma viral load, nadir CD4 cell count, or current CD4 count, did not 
show statistical significance. There were a total of 55 interruptions in the IG (STIs [41.8\%], patient's decision [36.3\%], and toxicity [21.8\%]). The remaining characteristics of the interruptions are shown in Table 2.

Neurocognitive impairment affected 16 patients (59.2\%) in the IG and 19 patients (33.9\%) in the NIG $(p=0.02)$. The percentages for HAND in both groups are shown in Table 1. The distribution was similar between groups, except for HAD, which was higher in the IG.

With regard to the scores representing neurocognitive domains, the comparison between groups revealed significant differences in the following functions: attention/working memory, specifically in digit span forward (IG, 46.8; NIG, 51.3 [ $p=0.03])$ and digit span backward (IG, 48.1; NIG, 53 [p=0.008]), and information processing speed in the SDMT written score (IG, 46; NIG, $50.6[p=0.01]$ ). These scores therefore indicated worse functioning in the IG. In fact, the remaining neuropsychological outcomes revealed that all scores were lower in the IG than in the NIG, thus indicating a general poorer functioning in this group, although the difference did not reach statistical significance. The differences in the scores representing neurocognitive domains are shown in Table 3.

An additional post hoc subanalysis was performed including all the scores in each neurocognitive domain assessed, and the mean was calculated for each of them. This was compared between groups, and the results showed statistically significant differences in attention/working memory. The outcomes of this analysis for the IG and NIG, respectively, were as follows: attention/working memory, 48.9 and $52.2(p=0.02)$; information processing speed, 49.6 and $51.8(p=0.24)$; verbal memory, 50.7 and $51.2(p=0.82)$; learning, 47.4 and $50.4(p=0.30)$; executive functions, 49.3 and $51.5(p=0.18)$; verbal fluency, 45.7 and 49.1 ( $p=0.07)$; and motor function, 51.9 and $54.8(p=0.22)$. Figure 2 summarizes the results for cognitive and motor functions in the form of a graph.

Because the study groups were not completely equivalent in terms of clinical variables, specifically with regard to time since diagnosis of HIV infection, a regression model was applied to assess the differences between neurocognitive scores, adjusting for time since diagnosis of HIV infection. This model revealed that significant differences between groups were maintained in the same cognitive and motor scores (digit span forward, $p=0.03$; digit span backward, $p=0.01$; and the SDMT written score, $p=0.02$ ). All $p$ 
values obtained by the regression model are included in Table 3. The results of Cohen's effect size tests confirmed these findings, thus revealing the presence of medium values according to the measures showing statistical significance. Specifically, 5 of the 15 sizes indicated medium values as the strongest size category found. These results are also included in Table 3.

\section{Discussion}

Detrimental consequences have been reported in HIV-infected persons who undergo structured treatment interruptions (Danel et al, 2006; El-Sadr et al, 2006; Ruíz et al, 2007). Our data support this finding, and reveal an association between interrupting antiretroviral therapy and presenting major impairment in neurocognitive functioning. We observed a higher prevalence of neurocognitive impairment in subjects who discontinued therapy in the past, and we also detected worse scores in neurocognitive functioning in the seven domains assessed, which were those habitually reported in other studies assessing impairment of neurocognitive functioning in HIV infection (Cysique et al, 2004; Heaton et al, 2009; Muñoz-Moreno, 2007; Muñoz-Moreno et al, 2008; Sacktor et al, 2002; Tozzi et al, 2005a). This strengthens our observations, and emphasizes the possible role of more vulnerable brain areas damaged by the effect of the virus, a hypothesis defended by other authors (Berger et al, 2000; Shapshack et al, 1999). The fact that we focused only on previous interruptions, and not on recent discontinuation of therapy, reinforces this supposition of irreversibility. Additionally, clinical trials evaluating large samples of subjects during CD4-guided interruptions of therapy have revealed higher rates of major cardiovascular, renal and hepatic diseases, opportunistic infections, and death (Danel et al, 2006; El-Sadr et al, 2006). However, factors such as the nadir CD4 cell count, baseline CD4 cell count, and other immunological and inflammatory parameters may affect end points (Caridello et al, 2005; Hirschel and Flanigan, 2009; Maggiolo et al, 2009; Sarmati et al, 2009; Seminari et al, 2008). Our objective was to study neurocognitive functioning in this setting, although we did not focus only on CD4-guided or structured treatment interruptions (41.8\% in our sample). We addressed this area from a more clinical perspective, namely, by examining possible long-term neurocognitive damage in individuals who had interrupted therapy in the past for any reason. 
At the 14th Conference on Retroviruses and Opportunistic Infections, Robertson and cols (Robertson et al, 2007) reported changes in the neurocognitive functioning evaluated before and after discontinuation of antiretroviral therapy in patients with high CD4 cell counts, observing an improvement in neurocognitive functioning at weeks 48, 72, and 96 after the interruption. Similarly, Childers and cols (Childers et al, 2008) recently reported that this practice could be safe and even slightly beneficial for neurocognitive functioning. Nevertheless, the study designs and objectives of both investigations were substantially different from ours, and this may explain the contradictory results. Both studies assessed participants based only on one treatment discontinuation, whereas the number of interruptions was unrestricted in our study. In fact, more than half of the individuals in our sample had discontinued treatment more than once (51.9\%). Furthermore, Robertson and cols presented information on subjects who discontinued therapy, but not on those who restarted therapy. In this regard, we firmly believe that data from subjects who restarted treatment is relevant in order to identify reversible and permanent damage. The results also differed in terms of immune status, which was represented by the nadir CD4 cell count. Unlike Robertson and cols, who selected participants with elevated nadir cell counts, we established our objectives independently of this value. Moreover, the nadir CD4 cell count is known to be one of the strongest predictors, both of the poor success of structured treatment interruptions (Maggiolo et al, 2004; Moltó et al, 2004), and neurocognitive impairment (Heaton et al, 2009; Muñoz-Moreno et al, 2008; Tozzi et al, 2005a). Thresholds of less than 350 cells $/ \mathrm{mm}^{3}$ have been associated with more likely disease events in patients interrupting therapy (Danel et al, 2006; El-Sadr et al, 2006; Ruíz et al, 2007), and also with a higher presence of neurocognitive dysfunction (Muñoz-Moreno et al, 2008). In our work, both study groups had similar nadir CD4 cell counts; therefore, we were unable to provide supplementary information on this interesting point. The prospective investigation of Childers and cols provided additional relevant information on neurocognitive functioning through measurement of valuable neuropsychological tests and CSF determinations. However, their study sample was small and the prevalence of neurocognitive impairment was relatively modest at baseline (three subjects, $27 \%$ of the sample). The investigators acknowledged that the rate of impairment at baseline could be significant enough to have a positive influence on the appearance of subsequent decline. Therefore, although the findings of Robertson and Childers seem to be different from ours, 
they should not be viewed as contradictory, chiefly because of the manifestly different study designs and population characteristics.

There is evidence in the literature to lead us to consider that antiretroviral therapy interruptions could be associated with a higher degree of neurocognitive dysfunction. Firstly, neurocognitive impairment has been associated with virological failure in plasma (Tozzi et al, 2005b). Moreover, elevated levels of HIV in CSF and plasma have been linked to neurocognitive decline (Ellis et al, 1997; Ellis et al, 2002; Ellis et al, 2003; Price et al, 2004). Findings such as these are increasingly common, and two preliminary therapeutic recommendations have been made for clinical practice, in contrast to interrupting therapy: the use of highly active antiretroviral drugs targeting CNS reservoirs (Letendre et al, 2004; Letendre et al, 2008; Tozzi et al, 2009), and the earlier initiation of HAART to protect CNS function (Arendt et al, 2007; Marcondes et al, 2009; McCrossan et al, 2006; MuñozMoreno et al, 2008; Panel on Clinical Practices for Treatment of HIV Infection convened by the Department of Health and Human Services [DHHS], 2009). Two ongoing randomized controlled clinical trials are analyzing both strategies (Clinical Trial of CNStargeted HAART [CIT2], 2010; Strategic Timing of Antiretroviral Treatment [START], 2010) and their results will provide useful information on the validity of both hypotheses. Secondly, interruption of therapy is linked to viral rebound in a substantial number of individuals (Deeks et al, 2001; Garcia et al, 2001; Harrigan et al, 1999; Tebas et al, 2002; Tubiana et al, 2002). Some authors describe the negative effects associated with marked reemergence of the virus, such as symptoms resembling those of acute retroviral disease (Knysz et al, 2005), rapid expansion of circulating CD8 T cells (Steingrover et al, 2008), or destruction of HIV-specific helper T cells (Davey et al, 1999; Oxenius et al, 2002; Scriba et al, 2005). Similar examples include the breakdown of the blood-brain barrier or microvascular changes brought about by early CNS inflammation, which induces the development of HIV dementia (Avison et al, 2004). In our work, comparisons involving attention/working memory and information processing speed revealed the most important differences, in contrast to other domains usually observed as altered in HIV infection, such as executive functioning. In this sense, prior reports have suggested the role of different types of involvement of neurocognitive domains, according to the distinct existence of inflammation or the influence of other risk factors (Berger et al, 2000; Castelo et al, 2006; Shapshak et al, 1999). Therefore, in our opinion, more intense neuroinflammation might be 
an alternative explanation for the poorer neurological status observed as a result of viral peaks affecting CNS functioning. Nevertheless, new research should surely focus on the neuropathological mechanisms involved in this hypothetical response of the brain to virological blips.

Our study has some limitations. The small sample size constrains the power of the results and, due to the cross-sectional design, possible associations with the interruptions were only studied retrospectively. In addition, it remains unclear whether neurocognitive problems could lead to interruption of therapy, although according to the weak rate of discontinuations for individual decisions (36.3\%), and the minority of participants with more than two interruptions (33.3\%), it seems that the decline in CNS functioning did not affect the decision to discontinue treatment. Finally, there were differences in the demographic and clinical conditions of the study groups, and time since HIV diagnosis was particularly significant. This may show a greater possibility of therapy discontinuation in patients who have had HIV infection for longer, although the linear regression model and additional effect size tests confirmed the initial results.

In summary, to date, several reports have described dysfunction of the CNS in people living with HIV, but few have explored the relationship between repeated antiretroviral treatment interruption and its consequences on neurocognitive performance. Our results are preliminary and based on a cross-sectional design, although they provide evidence of permanent neurocognitive dysfunctioning after antiretroviral therapy interruptions, mainly in attention/working memory and information processing speed. Therefore, we conclude that antiretroviral therapy interruptions may be an additional risk factor for neurocognitive impairment in HIV-infected patients and, as highlighted by other authors, we defend the importance of continuing antiretroviral therapy for the treatment of HIV-infected patients in order to protect neurocognitive functioning.

\section{Acknowledgements}

Sources of funding: This work was partially supported by grant 12355/02 from FIPSE (Fundación para la Investigación y la Prevención del SIDA en España), the Spanish AIDS network "Red Temática Cooperativa de Investigación en SIDA” (RD06/0006), and grant MTM2008-06747-C02-00 from the Ministerio de Ciencia e Innovación. 
Non-author contributions: We are grateful to Thomas O’Boyle for editorial assistance during the preparation of this manuscript.

Author contributions: Jose A. Muñoz-Moreno designed the study, analyzed data, drafted and critically reviewed the manuscript, and enrolled participants. Carmina R. Fumaz drafted and critically reviewed the manuscript, and enrolled participants. Anna Prats drafted and critically reviewed the manuscript, and enrolled participants. Maria J. Ferrer drafted and critically reviewed the manuscript, and enrolled participants. Eugènia Negredo drafted and critically reviewed the manuscript, and enrolled participants. Núria PérezÁlvarez analyzed data, and drafted and critically reviewed the manuscript. José Moltó drafted and critically reviewed the manuscript, and enrolled participants. Guadalupe Gómez analyzed data, and drafted and critically reviewed the manuscript. Maite Garolera drafted and critically reviewed the manuscript. Bonaventura Clotet drafted and critically reviewed the manuscript, and enrolled participants.

\section{References}

Antinori A, Arendt G, Becker JT, Brew BJ, Byrd DA, Cherner M, Clifford DB, Cinque P, Epstein LG, Goodkin K, Gisslen M, Grant I, Heaton RK, Joseph J, Marder K, Marra CM, McArthur JC, Nunn M, Price RW, Pulliam L, Robertson KR, Sacktor N, Valcour V, Wojna VE (2007). Updated research nosology for HIV-associated neurocognitive disorders. Neurology, 69, 1789-99.

Arendt G, Nolting T, Frisch C, Husstedt IW, Gregor N, Koutsilieri E, Maschke M, Angerer A, Obermann M, Neuen-Jacob E, Adams O, Loeffert S, Riederer P, ter Meulen V, Sopper S; German Competence Network HIV/AIDS (2007). Intrathecal viral replication and cerebral deficits in different stages of human immunodeficiency virus disease. J Neurovirol, 13, 225-32.

Avison MJ, Nath A, Greene-Avison R, Schmitt FA, Bales RA, Ethisham A, Greenberg RN, Berger JR (2004). Inflammatory changes and breakdown of microvascular integrity in early human immunodeficiency virus dementia. $J$ Neurovirol, 10, 223-32.

Beck AT, Rush AJ, Shaw BF, Emery G (1979). Cognitive Therapy of Depression. New York, NY: Guilford Press.

Beck AT, Steer RA, Brown GK (1996). Beck Depression Inventory: Manual BDI-II. New York, NY: Psychological Corporation.

Becker JT, Lopez OL, Dew MA, Aizenstein HJ (2004). Prevalence of cognitive disorders differs as a function of age in HIV virus infection. AIDS, 18, S11-8. 
Benton AL, Hamsher K, Sivan AB. Multilingual Aphasia Examination (1994). Iowa City, IA: AJA Associates.

Berger JR, Nath A, Greenberg RN, Andersen AH, Greene RA, Bognar A, Avison MJ (2000). Cerebrovascular changes in the basal ganglia with HIV dementia. Neurology, 54, 921-6.

Cardiello PG, Hassink E, Ananworanich J, Srasuebkul P, Samor T, Mahanontharit A, Ruxrungtham K, Hirschel B, Lange J, Phanuphak P, Cooper DA (2005). A prospective, randomized trial of structured treatment interruption for patients with chronic HIV type 1 infection. Clin Infect Dis, 40, 594-600.

Castelo JM, Sherman SJ, Courtney MG, Melrose RJ, Stern CE (2006). Altered hippocampal-prefrontal activation in HIV patients during episodic memory encoding. Neurology, 66, 1688-95.

Childers ME, Woods SP, Letendre S, McCutchan JA, Rosario D, Grant I, Mindt MR, Ellis RJ (2008). Cognitive functioning during highly active antiretroviral therapy interruption in human immunodeficiency virus type 1 infection. $J$ Neurovirol, 18, 1-8.

Clinical Trial of CNS-targeted HAART (CIT2). ClinicalTrials.gov Identifier: NCT00624195. December $2009 . \quad$ Available: http://www.clinicaltrials.gov/ct2/show/study/NCT00624195?term=CIT+2+hiv\&rank=1 via the INTERNET. Accessed 2010 Jan 27.

Cohen J (1988). Statistical Power Analysis for the Behavioral Sciences (2nd. ed.) Hillsdale, NJ: Erlbaum.

Culbertson WC, Zillmer EA. Tower of London - Drexel University (TOL ${ }^{\mathrm{DX}}$ ) (2001). Canada: Multi-Health Systems Inc Toronto.

Cysique LA, Maruff P, Brew BJ (2004). Prevalence and pattern of neuropsychological impairment in human immunodeficiency virus-infected/acquired immunodeficiency syndrome (HIV/AIDS) patients across pre- and post-highly active antiretroviral therapy eras: a combined study of two cohorts. J Neurovirol, 10, 350-7.

Cysique LA, Maruff P, Brew BJ (2006). Variable benefit in neuropsychological function in HIV-infected HAART-treated patients. Neurology, 66, 1447-50.

Danel C, Moh R, Minga A, Anzian A, Ba-Gomis O, Kanga C, Nzunetu G, Gabillard D, Rouet F, Sorho S, Chaix ML, Eholié S, Menan H, Sauvageot D, Bissagnene E, Salamon R, Anglaret X; Trivacan ANRS 1269 Trial Group (2006). CD4-guided structured antiretroviral treatment interruption strategy in HIV-infected adults in west Africa (Trivacan ANRS 1269 trial): a randomised trial. Lancet, 367, 1981-9.

Davey, RT Jr, Bat N, Yoder C, Chun TW, Metcalf JA, Dewar R, Natarajan V, Lempicki RA, Adelsberger JW, Miller KD, Kovacs JA, Polis MA, Walker RE, Falloon 
J, Masur H, Gee D, Baseler M, Dimitrov DS, Fauci AS, Lane HC (1999). HIV-1 and T cell dynamics after interruption of highly active antiretroviral therapy (HAART) in patients with a history of sustained viral suppression. Proc Natl Acad Sci U S A, 96, 15109-15114.

Deeks SG, Wrin T, Liegler T, Hoh R, Hayden M, Barbour JD, Hellmann NS, Petropoulos CJ, McCune JM, Hellerstein MK, Grant RM (2001). Virologic and immunologic consequences of discontinuing combination antiretroviral-drug therapy in HIV-infected patients with detectable viremia. $N$ Engl J Med, 344, 472-80.

Delis DC, Kramer JH, Kaplan E, Ober BA (2000). California Verbal Learning Test. New York, NY: The Psychological Corporation.

Ellis RJ, Hsia K, Spector SA, Nelson JA, Heaton RK, Wallace MR, Abramson I, Atkinson JH, Grant I, McCutchan JA (1997). Cerebrospinal fluid human immunodeficiency virus type 1 RNA levels are elevated in neurocognitively impaired individuals with acquired immunodeficiency syndrome. HIV Neurobehavioral Research Center Group. Ann Neurol, 42, 679-88.

Ellis RJ, Moore DJ, Childers ME, Letendre S, McCutchan JA, Wolfson T, Spector SA, Hsia K, Heaton RK, Grant I (2002). Progression to neuropsychological impairment in human immunodeficiency virus infection predicted by elevated cerebrospinal fluid levels of human immunodeficiency virus RNA. Arch Neurol, 59, 923-8.

Ellis RJ, Childers ME, Zimmerman JD, Frost SD, Deutsch R, McCutchan JA; HIV. Neurobehavioral Research Center Group (2003). Human immunodeficiency virus-1 RNA levels in cerebrospinal fluid exhibit a set point in clinically stable patients not receiving antiretroviral therapy. J Infect Dis, 187, 1818-21.

El-Sadr WM, Lundgren JD, Neaton JD, Gordin F, Abrams D, Arduino RC, Babiker A, Burman W, Clumeck N, Cohen CJ, Cohn D, Cooper D, Darbyshire J, Emery S, Fätkenheuer G, Gazzard B, Grund B, Hoy J, Klingman K, Losso M, Markowitz N, Neuhaus J, Phillips A, Rappoport C; Strategies for Management of Antiretroviral Therapy (SMART) Study Group (2006). CD4+ count-guided interruption of antiretroviral treatment. $N$ Engl J Med, 355, 2283-96.

García F, Plana M, Ortiz GM, Bonhoeffer S, Soriano A, Vidal C, Cruceta A, Arnedo M, Gil C, Pantaleo G, Pumarola T, Gallart T, Nixon DF, Miró JM, Gatell JM (2001). The virological and immunological consequences of structured treatment interruptions in chronic HIV-1 infection. AIDS, 15, F29-40.

Gladsjo JA, Schuman CC, Evans JD, Peavy GM, Miller SW, Heaton RK (1999). Norms for letter and category fluency: Demographic corrections for age, education, and ethnicity. Assessment 6, 147-78.

Golden CJ. Stroop Color and Word Test: A Manual for Clinical and Experimental Uses (1978). Wood Dale, IL: Stoetling Company. 
Golden CJ. Stroop (2001). Test de Colores y Palabras. Madrid: TEA Ediciones.

Harrigan PR, Whaley M, Montaner JS (1999). Rate of HIV-1 RNA rebound upon stopping antiretroviral therapy. AIDS, 13, F59-62.

Heaton R, Franklin D, Clifford D, Woods S, Rivera M, Vigil O, Taylor M, Marcotte T, Atkinson H, Grant I; CHARTER Study Group (2009). HIV-associated Neurocognitive Impairment Remains Prevalent in the Era of Combination ART: The CHARTER Study. In: The 16th Conference on Retroviruses and Opportunistic Infections, February 8-11, 2009, Montreal, Canada. Abstract 154.

Hilsabeck RC, Castellon SA, Hinkin CH (2005). Neuropsychological aspects of coinfection with HIV and hepatitis C virus. Clin Infect Dis, 41, S38-44.

Hirschel B, Flanigan T (2009). Is it smart to continue to study treatment interruptions? AIDS, 23, 757-9.

Knysz B, Gasiorowski J, Czarnecki M, Gladysz A (2005). Viral rebound syndrome in two HIV-1-positive patients after structured treatment interruption. Viral Immunol, 18, 579-81.

Kongs SK, Thompson LL, Iverson GL, Heaton RK. Wisconsin Card Sorting Test -64 card computerized version (1993). Odessa, FL: Psychological Assessment Resources.

Letendre SL, McCutchan JA, Childers ME, Woods SP, Lazzaretto D, Heaton RK, Grant I, Ellis RJ; HNRC Group (2004). Enhancing antiretroviral therapy for human immunodeficiency virus cognitive disorders. Ann Neurol, 56, 416-23.

Letendre SL, Marquie-Beck J, Capparelli E, Best B, Clifford D, Collier AC, Gelman BB, McArthur JC, McCutchan JA, Morgello S, Simpson D, Grant I, Ellis RJ; CHARTER Group (2008). Validation of the CNS Penetration-Effectiveness rank for quantifying antiretroviral penetration into the central nervous system. Arch Neurol, 65, 65-70.

Maggiolo F, Ripamonti D, Gregis G, Quinzan G, Callegaro A, Suter F (2004). Effect of prolonged discontinuation of successful antiretroviral therapy on CD4 T cells: a controlled, prospective trial. AIDS, 18, 439-46.

Maggiolo F, Airoldi M, Callegaro A, Martinelli C, Dolara A, Bini T, Gregis G, Quinzan G, Ripamonti D, Ravasio V, Suter F (2009). CD4 cell-guided scheduled treatment interruptions in HIV-infected patients with sustained immunologic response to HAART. AIDS, 23, 799-807.

Marcondes MC, Flynn C, Huitron-Rezendiz S, Watry DD, Zandonatti M, Fox HS (2009). Early antiretroviral treatment prevents the development of central nervous system abnormalities in simian immunodeficiency virus-infected rhesus monkeys. AIDS, 23, 1187-95. 
Matthews CG, Klove H (1964). Instruction Manual for the Adult Neuropsychology Test Battery. Madison, WI: University of Wisconsin Medical School.

McCrossan M, Marsden M, Carnie FW, Minnis S, Hansoti B, Anthony IC, Brettle RP, Bell JE, Simmonds P (2006). An immune control model for viral replication in the CNS during presymptomatic HIV infection. Brain, 129, 503-16.

Moltó J, Ruiz L, Romeu J, Martínez-Picado J, Negredo E, Tural C, Sirera G, Clotet B (2004). Influence of prior structured treatment interruptions on the length of time without antiretroviral treatment in chronically HIV-infected subjects. AIDS Res Hum Retroviruses, 20, 1283-8.

Muñoz-Moreno, JA (2007). Neurocognitive and motor disorders in HIV infection. Assessment and interventions. In Research Focus on Cognitive Disorders. In Plishe, VN (eds). Hauppauge, NY: Nova Science Publishers Inc.

Muñoz-Moreno JA, Fumaz CR, Ferrer MJ, Prats A, Negredo E, Garolera M, PérezÁlvarez N, Moltó J, Gómez G, Clotet B (2008). Nadir CD4 cell count predicts neurocognitive impairment in HIV-infected patients. AIDS Res Hum Retroviruses, 24, 1301-7.

Muñoz-Moreno JA, Letendre S, McClernon D, Ellis R, Leblanc S, Rosario D, Clifford D, Collier A, Gelman B, Marra CM, McArthur J, McCutchan A, Morgello S, Simpson D, Franklin D, Heaton R, Grant I; CHARTER Study Group (2009). Persistent HIV in the Central Nervous System during Treatment is Associated with Worse ART Penetration and Cognitive Impairment. In: The 9th International Symposium on Neurovirology, June 2-6 June, 2009, Miami, Florida, USA. Abstract P130.

Oxenius, A, Price DA, Günthard HF, Dawson SJ, Fagard C, Perrin L, Fischer M, Weber R, Plana M, García F, Hirschel B, McLean A, Phillips RE (2002). Stimulation of HIV-specific cellular immunity by structured treatment interruption fails to enhance viral control in chronic HIV infection. Proc Natl Acad Sci USA, 99, 13747-52.

Panel on Clinical Practices for Treatment of HIV Infection convened by the Department of Health and Human Services (DHHS). Guidelines for the use of antiretroviral agents in HIV-infected adults and adolescents. December 2009. Available: http://aidsinfo.nih.gov/ContentFiles/AdultandAdolescentGL.pdf via the INTERNET. Accessed 2010 Jan 27.

Price RW, Deeks SG (2004). Antiretroviral drug treatment interruption in human immunodeficiency virus-infected adults: Clinical and pathogenetic implications for the central nervous system. J Neurovirol, 10, S44-51.

Reitan RM, Davidson LA (1974). Clinical Neuropsychology: Current Status and Applications. New York, NY: John Wiley \& Sons.

Reitan RM, Wolfson D (1985a). Trail Making Test. The Halstead-Reitan Neuropsychological Test Battery. Tucson, AZ: Neuropsychology Press. 
Reitan RM, Wolfson D (1985b). Grooved Pegboard. The Halstead-Reitan Extended Neuropsychological Test Battery. Tucson, AZ: Neuropsychology Press.

Robertson K, Su Z, Krambrink A, Evans S, Havlir V, Margolis D, Skiest D; ACTG 5170 team (2007). This Is Your Brain Off Drugs: Neurocognitive Function before and after ART Discontinuation in Patients with High CD4 Nadir (ACTG A5170). In: The 14th Conference on Retroviruses and Opportunistic Infections, February 25-28, Los Angeles, California, USA. Abstract 113.

Ruíz L, Paredes R, Gomez G, Romeu J, Domingo P, Perez-Alvarez N, Tambussi G, Llibre JM, Martínez-Picado J, Vidal F, Fumaz CR, Clotet B; TIBET Study Group (2007). Antiretroviral therapy interruption guided by CD4 cell counts and plasma HIV1 RNA levels in chronically HIV-1-infected patients. AIDS, 21, 169-78.

Sacktor N, McDermott MP, Marder K, Schifitto G, Selnes OA, McArthur JC, Stern Y, Albert S, Palumbo D, Kieburtz K, De Marcaida JA, Cohen B, Epstein L (2002). HIVassociated cognitive impairment before and after the advent of combination therapy. $J$ Neurovirol, 8, 136-42.

Sarmati L, Andreoni C, Nicastri E, Tommasi C, Buonomini A, D'Ettorre G, Corpolongo A, Dori L, Montano M, Volpi A, Narciso P, Vullo V, Andreoni M (2009). Prognostic factors of long-term CD4+count-guided interruption of antiretroviral treatment. J Med Virol, 81, 481-7.

Scriba TJ, Zhang HT, Brown HL, Oxenius A, Tamm N, Fidler S, Fox J, Weber JN, Klenerman P, Day CL, Lucas M, Phillips RE (2005). HIV-1-specific CD4+ T cell turnover and activation increase upon viral rebound. J Clin Invest, 115, 443-50.

Seminari E, De Silvestri A, Boschi A, Tinelli C (2008). CD4+ guided antiretroviral treatment interruption in HIV infection: a meta-analysis. AIDS Rev, 10, 236-44.

Shapshak P, Segal DM, Crandall KA, Fujimura RK, Zhang BT, Xin KQ, Okuda K, Petito CK, Eisdorfer C, Goodkin K (1999). Independent evolution of HIV type 1 in different brain regions. AIDS Res Hum Retroviruses, 15, 811-20.

Smith A. Symbol Digit Modalities Test (SDMT) (1973). Los Angeles, CA: Western Psychological Services.

Smith, A. Test de Símbolos y Dígitos (SDMT) (2002). Madrid: TEA Ediciones.

Spielberger CD, Gorsuch RL, Lushene RE (1970). Manual for the State-Trait Anxiety Inventory. Palo Alto, CA: Consulting Psychologists Press.

Spudich SS, Huang W, Nilsson AC, Petropoulos CJ, Liegler TJ, Whitcomb JM, Price RW (2005). HIV-1 chemokine coreceptor utilization in paired cerebrospinal fluid and plasma samples: a survey of subjects with viremia. J Infect Dis, 191, 890-8. 
Steingrover R, Pogány K, Fernandez Garcia E, Jurriaans S, Brinkman K, Schuitemaker H, Miedema F, Lange JM, Prins JM (2008). HIV-1 viral rebound dynamics after a single treatment interruption depends on time of initiation of highly active antiretroviral therapy. AIDS, 22, 1583-8.

Strategic Timing of Antiretroviral Treatment (START). ClinicalTrials.gov Identifier: NCT00867048. December 2009.2 Available: http://www.clinicaltrials.gov/ct2/show/NCT00867048?term=start+neurologic+hiv\&ran $\mathrm{k}=1$ via the INTERNET. Accessed 2010 Jan 27.

Tebas P, Henry K, Mondy K, Deeks S, Valdez H, Cohen C, Powderly WG (2002). Effect of prolonged discontinuation of successful antiretroviral therapy on CD4+ T cell decline in human immunodeficiency virus-infected patients: implications for intermittent therapeutic strategies. J Infect Dis, 186, 851-4.

Tozzi V, Balestra P, Lorenzini P, Bellagamba R, Galgani S, Corpolongo A, et al. Vlassi C, Larussa D, Zaccarelli M, Noto P, Visco-Comandini U, Giulanelli M, Ippolito G, Antinori A, Narciso P (2005a). 1996 to 2002: results from an urban observational cohort. J Neurovirol, 11, 265-73.

Tozzi V, Balestra P, Serraino D, Bellagamba R, Corpolongo A, Piselli P, Lorenzini P, Visco-Comandini U, Vlassi C, Quartuccio ME, Giulianelli M, Noto P, Galgani S, Ippolito G, Antinori A, Narciso P (2005b). Neurocognitive impairment and survival in a cohort of HIV-infected patients treated with HAART. AIDS Res Hum Retroviruses, 21, 706-13.

Tozzi V, Balestra P, Bellagamba R, Corpolongo A, Salvatori MF, Visco-Comandini U, Vlassi C, Giulanelli M, Galgani S, Antinori A, Narciso P (2007). Persistence of neuropsychologic deficits despite long-term highly active antiretroviral therapy in patients with HIV-related neurocognitive impairment: prevalence and risk factors. $J$ Acquir Immune Defic Syndr, 45, 174-82.

Tozzi V, Balestra P, Salvatori MF, Vlassi C, Liuzzi G, Giancola ML, Giulianelli M, Narciso P, Antinori A (2009). Changes in cognition during antiretroviral therapy: comparison of 2 different ranking systems to measure antiretroviral drug efficacy on HIV-associated neurocognitive disorders. J Acquir Immune Defic Syndr, 52, 56-63.

Tubiana R, Ghosn J, De-Sa M, Wirden M, Gautheret-Dejean A, Bricaire F, Katlama C (2002). Warning: antiretroviral treatment interruption could lead to an increased risk of HIV transmission. AIDS, 16, 1083-91.

Weschler D (1997). Wechsler Adult Intelligence Scale - Third Edition (WAIS-III). Administration and scoring manual. San Antonio, TX: The Psychological Corporation.

Wechsler D (1999). Escala de Inteligencia Wechsler para Adultos (WAIS-III) (3 ${ }^{\text {a }}$ Ed.). Madrid: TEA Ediciones. 